\title{
Giant isothermal entropy change In (111)-oriented PMN-PT thin film
}

\author{
Mahmoud A. Hamad \\ Physics Department, Faculty of Science \\ Tanta University, Tanta, Egypt \\ m_hamad76@yahoo.com
}

Received 29 August 2014; Revised 4 October 2014; Accepted 16 October 2014; Published 13 November 2014

\begin{abstract}
An isothermal entropy change of $240 \mathrm{~nm}$ (111)-oriented PMN-PT 65/35 film near the ferroelectric Curie temperature, relative cooling power (RCP) and change of heat capacity have been investigated. The extracted data characterized giant isothermal entropy change of more than $16 \mathrm{~J} / \mathrm{kg} \mathrm{K}$ in electric field shift $\Delta E$ of $455 \mathrm{kV} \mathrm{cm}^{-1}$, which is nearly twice than that found for $\mathrm{PbZr}_{0.95} \mathrm{Ti}_{0.05} \mathrm{O}_{3}$ thin film at $492 \mathrm{kV} \mathrm{cm}^{-1}$ near the Curie point. Furthermore, the RCP $\approx 700 \mathrm{~J} / \mathrm{kg}$ and change of heat capacity $\approx 233 \mathrm{~J} / \mathrm{kg} \mathrm{K}$ in electric field shift $\Delta E$ of $747 \mathrm{kV} \mathrm{cm}^{-1}$.
\end{abstract}

Keywords: Electrocaloric effect; PMN-PT thin film; polarization; entropy change; heat capacity change.

The search for materials showing caloric effects has become a challenge in modern materials physics and it is expected that such a group of materials will give a way to renovate present cooling devices that are based on the vapor compression of hazardous gases. Till now, the most promising materials are electrocaloric and magnetocaloric materials. ${ }^{1-13}$ Ferroelectric materials $(1-x) \mathrm{PbMg}_{1 / 3} \mathrm{Nb}_{2 / 3} \mathrm{O}_{3}-x \mathrm{PbTiO}_{3}$ with the compositions near the morphotropic phase boundary are promising for microelectro-mechanical systems and high-strain actuators/transducers due to their well-known ferroelectric, dielectric, and piezoelectric properties. ${ }^{14-20}$

The electrocaloric effect (ECE) of (111) $0.65 \mathrm{PbMg}_{1 / 3^{-}}$ $\mathrm{Nb}_{2 / 3} \mathrm{O}_{3}-0.35 \mathrm{PbTiO}_{3}(\mathrm{PMN}-\mathrm{PT}$ 65/35) thin films near the Curie point has been studied. ${ }^{21}$ This study reported an electrocaloric temperature change $\Delta T$ of $31 \mathrm{~K}(\Delta E=747 \mathrm{kV} / \mathrm{cm})$ for a (111) PMN-PT 65/35 thin film deposited on a substrate $\left(\mathrm{Pt}(111) / \mathrm{TiO}_{2} / \mathrm{SiO}_{2} / \mathrm{Si}\right)$. This paper computs the electrocaloric properties of ferroelectric (111) PMN-PT 65/35 thin film such as entropy changes, heat capacity changes, and relative cooling power (RCP) at various applied electric field shifts that were not included in Ref. 21.

According to the phenomenological model, ${ }^{22}$ the dependence of polarization on variation of temperature and Curie temperature $\left(T_{c}\right)$ is presented by

$$
P=\left(\frac{P_{i}-P_{f}}{2}\right)\left[\tanh \left(A\left(T_{C}-T\right)\right)\right]+B T+C,
$$

where $P_{i}$ is an initial value of polarization at ferroelectricparaelectric transition and $P_{f}$ is a final value of polarization at ferroelectric-paraelectric transition as shown as in Fig. 1.
$A=\frac{2\left[B-\frac{d P}{d T} \mid T=T_{C}\right]}{P_{i}-P_{f}}, B$ is polarization sensitivity $\frac{d P}{d T}$ at ferroelectric state before transition, $\left.\frac{d P}{d T}\right|_{T=T_{C}}$ is polarization sensitivity $\frac{d P}{d T}$ at Curie temperature $T_{c}$, and $C=\frac{P_{f}+P_{i}}{2}-B T_{C}$.

A result of this phenomenological model, the electrocaloric entropy change $\Delta S^{E}$ caused by variation of the external electric field from $E_{1}$ to $E_{2}$ is given by

$$
\begin{aligned}
\Delta S^{E}= & \left(-A\left(\frac{P_{i}-P_{f}}{2}\right)\right. \\
& \left.\times \operatorname{sech}^{2}\left(A\left(T_{C}-T\right)\right)+B\right) \times \frac{\Delta E}{\rho},
\end{aligned}
$$

where $\rho$ is the mass density and $\Delta E=E_{2}-E_{1}$.

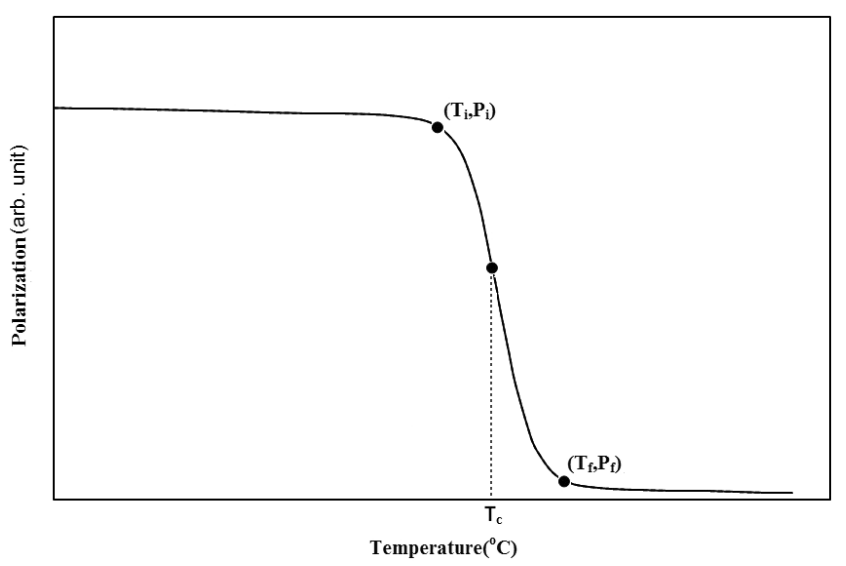

Fig. 1. Dependence of polarization as a function of temperature is described by Eq. (1).

This is an Open Access article published by World Scientific Publishing Company. It is distributed under the terms of the Creative Commons Attribution 3.0 (CC-BY) License. Further distribution of this work is permitted, provided the original work is properly cited. 
A main result of Eq. (2) is maximum entropy change $\Delta S_{\text {Max }}^{E}$ (where $T=T_{c}$ ), is expressed as follows:

$$
\Delta S_{\text {Max }}^{E}=\left(-A\left(\frac{P_{i}-P_{f}}{2}\right)+B\right) \times \frac{\Delta E}{\rho} .
$$

According to the phenomenological model, a full-width at half-maximum $\delta T_{\mathrm{FWHM}}$ can be calculated as follows ${ }^{22}$ :

$$
\delta T_{\mathrm{FWHM}}=\frac{2}{A} \cosh ^{-1}\left(\sqrt{\frac{2 A\left(P_{i}-P_{f}\right)}{A\left(P_{i}-P_{f}\right)+2 B}}\right) .
$$

An electrocaloric cooling efficiency is calculated by considering the magnitude of maximum electrocaloric entropy change, $-\Delta S_{\text {Max }}^{E}$ and its full-width at half-maximum $\left(\delta T_{\mathrm{FWHM}}\right) .^{23}$ A product of $-\Delta S_{\mathrm{Max}}^{E}$ and $\delta T_{\mathrm{FWHM}}$ is called RCP based on electrocaloric entropy change.

$$
\begin{aligned}
\mathrm{RCP}= & -\Delta S_{\mathrm{Max}}^{E}(T, \Delta E) \times \delta T_{\mathrm{FWHM}}, \\
= & \left(P_{i}-P_{f}-2 \frac{B}{A}\right) \times \frac{\Delta E}{\rho} \\
& \times \cosh ^{-1}\left(\sqrt{\frac{2 A\left(P_{i}-P_{f}\right)}{A\left(P_{i}-P_{f}\right)+2 B}}\right) .
\end{aligned}
$$

A polarization-related change of heat capacity is given by

$$
\Delta C_{P, E}=T \frac{\delta \Delta S^{E}}{\delta T} .
$$

According to this phenomenological model, a change of heat capacity is given by

$$
\begin{aligned}
\Delta C_{P, E}= & -T A^{2}\left(P_{i}-P_{f}\right) \operatorname{sech}^{2}\left(A\left(T_{C}-T\right)\right) \\
& \times\left(\tanh \left(A\left(T_{C}-T\right)\right)\right) \frac{\Delta E}{\rho} .
\end{aligned}
$$

A temperature change of a polar system under adiabatic electric field variation from an initial value $E_{1}$ to final value $E_{2}$, can be written in the form

$$
\begin{aligned}
\Delta T & =-\frac{T}{C_{E} \rho} \int_{E_{1}}^{E_{2}}\left(\frac{\partial P}{\partial T}\right)_{E} d E, \\
& =\frac{A T\left(P_{i}-P_{f}\right)}{2 C_{E} \rho}\left[\operatorname{sech}^{2}\left(A\left(T_{C}-T\right)\right)+B\right] \Delta E .
\end{aligned}
$$

$C_{E}$ is a heat capacity per mole at constant electric field.
The refrigerant capacity (RC) is, the amount of heat that can be transferred in one thermodynamic cycle. ${ }^{24}$ Here, RC values can be obtained as follows. ${ }^{22}$

$$
\begin{aligned}
\mathrm{RC}= & \int_{T_{C}-\frac{\delta T_{\mathrm{FWHM}}}{2}}^{T_{C}+\frac{\delta T_{\mathrm{FWHM}}}{2}} \Delta S^{E} d T, \\
= & {\left[-\left(P_{i}-P_{f}\right) \times \tanh \left(A \frac{\delta T_{\mathrm{FWHM}}}{2}\right)\right.} \\
& \left.+B \delta T_{\mathrm{FWHM}}\right] \frac{\Delta E}{\rho} .
\end{aligned}
$$

From this phenomenological model, the values of $\delta T_{\mathrm{FWHM}}$, $\left|\Delta S_{E}\right|_{\text {Max }},|\Delta T|_{\text {Max }}, \mathrm{RCP}, \mathrm{RC}$, and $\Delta C$ for (111) PMN-PT $65 / 35$ thin film due to applied electric field shift $\Delta E$ can be easily calculated.

In order to apply the phenomenological model, five parameters versus applied electric field were determined as displayed in Table 1 . In the temperature range of interest, a heat capacity of $C_{p}=120 \mathrm{~J} \mathrm{~mol}^{-1} \mathrm{~K}^{-1}=377 \mathrm{~J} \mathrm{Kg}^{-1} \mathrm{~K}^{-1}$ and mass density $\rho=8.08 \mathrm{~g} \cdot \mathrm{cm}^{-3}$ for PMN-PT $65 / 35$ thin film has been considered. ${ }^{21}$

Figure 2 shows polarization variation induced by temperature change at different electric fields for (111)-oriented PMN-PT 65/35 film. The symbols in Fig. 2 represent experimental data from Ref. 21 and the dashed lines represent simulated data. It is clear that Fig. 2 shows a good agreement between simulated results and experimental data. EC entropy changes associated with the ferroelectric-paraelectric transition are shown in Fig. 3. The extracted data characterized giant isothermal entropy change of more than $16 \mathrm{~J} / \mathrm{kg} \mathrm{K}$ in electric field shift $\Delta E$ of $455 \mathrm{kV} \mathrm{cm}^{-1}$, which is nearly twice than that found for $\mathrm{PbZr}_{0.95} \mathrm{Ti}_{0.05} \mathrm{O}_{3}$ thin film in $492 \mathrm{kV} \mathrm{cm}{ }^{-1}$ near the Curie point. ${ }^{1}$

In Fig. 4, the predicted heat capacity changes and temperature changes are shown as functions of temperature under different electric field shifts, calculated from Eqs. (7) and (8), respectively.

The extracted data characterized the electrocaloric temperature change, up to $31.21 \mathrm{~K}$ at $17.928 \mathrm{~V}$ (i.e., $1.74 \mathrm{KV}^{-1}$ ) near the Curie point at temperatures around $138^{\circ} \mathrm{C}$. This value is closer to the previous work $(\Delta T=31 \mathrm{~K}) .^{21}$

From Fig. 4, the (111)-oriented PMN-PT 65/35 film has a giant change in heat capacity to more than $200 \mathrm{~J} / \mathrm{kg} \mathrm{K}$. At an electric field shift of $747 \mathrm{kV} \mathrm{cm}^{-1}$, using Eqs. (5) and (9), the

Table 1. Model parameters for (111) PMN-PT 65/35 thin film at various applied electric fields.

\begin{tabular}{lccccc}
\hline$E\left(\mathrm{kV} \mathrm{cm}^{-1}\right)$ & $T_{c}\left({ }^{\circ} \mathrm{C}\right)$ & $P_{i}\left(\mu \mathrm{C} \cdot \mathrm{cm}^{-2}\right)$ & $P_{f}\left(\mu \mathrm{C} \cdot \mathrm{cm}^{-2}\right)$ & $B\left(\mu \mathrm{C} \cdot \mathrm{cm}^{-2} \cdot{ }^{\circ} \mathrm{C}^{-1}\right)$ & $\left.\frac{d P}{d T}\right|_{T=T_{C}}\left(\mu \mathrm{C} \cdot \mathrm{cm}^{-2} \cdot{ }^{\circ} \mathrm{C}^{-1}\right)$ \\
\hline 455 & 138 & 38.36 & 33.11 & -0.011 & -0.31 \\
502 & 138 & 40.12 & 34.4 & -0.011 & -0.31 \\
554 & 138 & 42.38 & 35.94 & -0.011 & -0.31 \\
605 & 138 & 44.21 & 37.45 & -0.011 & -0.31 \\
654 & 138 & 45.55 & 38.43 & -0.011 & -0.31 \\
747 & 138 & 47.46 & 39.43 & -0.011 & -0.31 \\
\hline
\end{tabular}




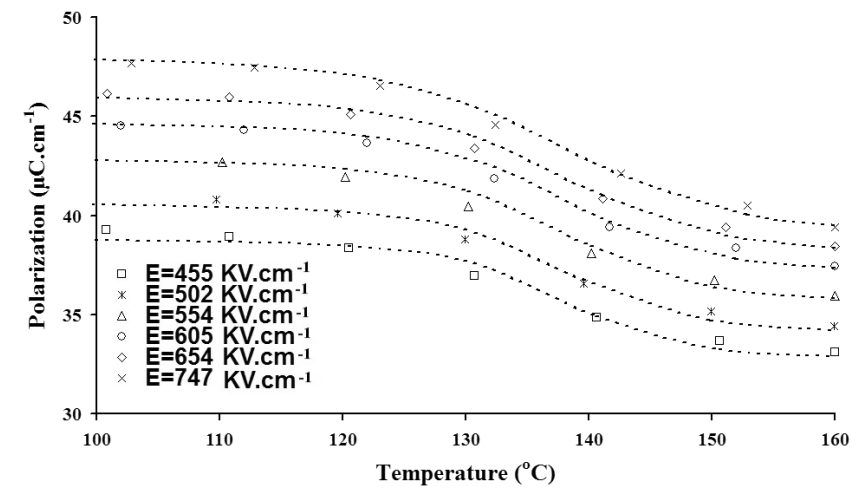

Fig. 2. Polarization variation induced by temperature change under different electric field for (111) PMN-PT 65/35 thin film. The dashed lines are modeled results by Eq. (1) and symbols represent experimental data from Ref. 21.

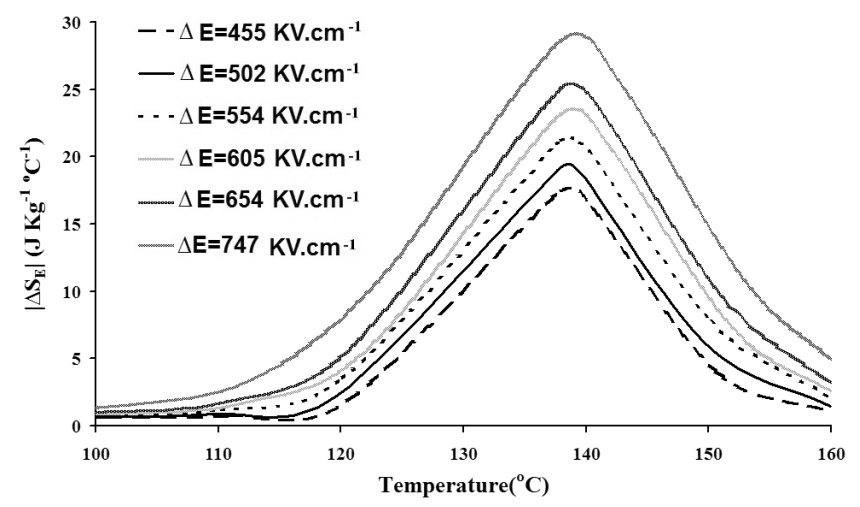

Fig. 3. Absolute values of electrocaloric entropy changes versus temperature at various applied electric field shifts for (111) PMNPT 65/35 thin film.

values of RCP and RC are 698.6 and $559.3 \mathrm{~J} / \mathrm{kg}$, respectively. Therefore, (111) PMN-PT 65/35 thin film shows a giant ECE near the Curie point. This may be attributed to the significant contribution of the latent heat from the fieldinduced phase transition and the choice of the substrate $\left(\mathrm{Pt}(111) / \mathrm{TiO}_{2} / \mathrm{SiO}_{2} / \mathrm{Si}\right)$ which has, through the interfacial strain, enhanced the ECE. The control of the misfit strain by appropriate choice of substrate provides potential means to vary both the magnitude and the temperature sensitivity of the ECE for use in cooling or thermodielectric power conversion devices. ${ }^{25}$ Another contributing factor can be the orientation of the epitaxial films that activates the strongest EC tensor element, as well as the high film crystallinity. ${ }^{26}$ Furthermore, PMN-PT thin-film processing is a challenge due to the persistence of a pyrochlore phase and high porosity. Pyrochlore phases and porosity have been pointed out as the main factors contributing to the decrease of dielectric and ferroelectric properties. ${ }^{27-30}$

The addition of the (111) PMN-PT 65/35 shows a giant ECE, the pyroelectric effect of (111) PMN-PT 65/35 thin

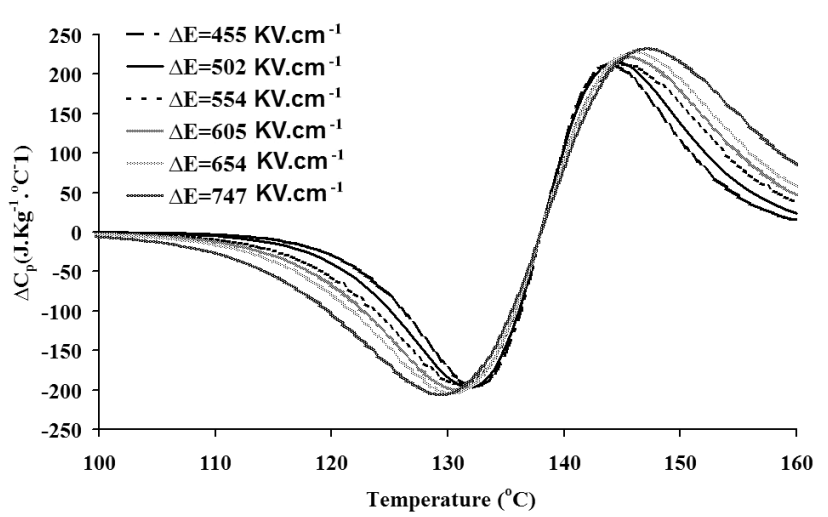

(a)

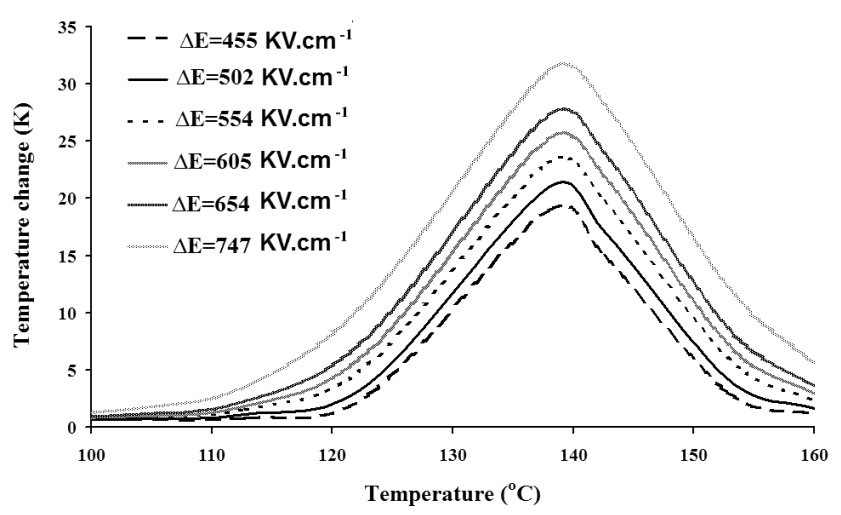

(b)

Fig. 4. (a) Heat capacity changes and (b) Electrocaloric temperature changes for (111) PMN-PT 65/35 thin film at various applied electric field shifts versus temperature.

film can recover useful electrical power from waste heat. Therefore, electrical triggering of the cooling of (111) PMN-PT 65/35 thin film is more practical. Finally, in phenomenological model, it can calculate the electrocaloric properties of (111) PMN-PT 65/35 thin film with limited processing time. Moreover, the model does not add any auxiliary computational efforts to the numerical simulation. Our results resolve the controversy surrounding macroscopic models of the ECE and may inspire ab initio calculations of electrocaloric parameters and thus a targeted search for new materials.

In conclusion, ECE of (111)-oriented PMN-PT 65/35 is calculated showing promising results. The extracted data characterized an isothermal entropy change of more than $28 \mathrm{~J} /$ $\mathrm{kg} \mathrm{K}, \mathrm{RCP} \approx 700 \mathrm{~J} / \mathrm{kg}$ and change of heat capacity $\approx 233 \mathrm{~J} /$ $\mathrm{kg} \mathrm{K}$ in electric field shift $\Delta E$ of $747 \mathrm{kV} \mathrm{cm}^{-1}$.

In conclusion, a giant ECE in this sample suggests that a large family of layered perovskite oxides might exhibit analogical feature. The simulation shows more potential of ECE by this model can be easily worked out, which constitutes the main originality. 


\section{References}

${ }^{1}$ M. A. Hamad, Theoretical investigations on electrocaloric properties of $\mathrm{PbZr}_{0.95} \mathrm{Ti}_{0.05} \mathrm{O}_{3}$ thin film, Int. J. Thermophys. 34, 11581165 (2013).

${ }^{2}$ M. A. Hamad, Magnetocaloric effect in half-metallic double perovskite $\mathrm{Sr}_{0.4} \mathrm{Ba}_{1.6-\mathrm{x}} \mathrm{Sr}_{x} \mathrm{FeMoO}_{6}$, Int. J. Thermophys. 34, 2144 2151 (2013).

${ }^{3}$ M. A. Hamad, Magnetocaloric effect in $\mathrm{La}_{1-x} \mathrm{Cd}_{x} \mathrm{MnO}_{3}, J$. Supercond. Nov. Magn. 26, 3459-3462 (2013).

${ }^{4}$ M. A. Hamad, Magnetocaloric effect in $\mathrm{La}_{0.7} \mathrm{Sr}_{0.3} \mathrm{MnO}_{3} / \mathrm{Ta}_{2} \mathrm{O}_{5}$ Composites, J. Adv. Ceram. 2, 213-217 (2013).

${ }^{5} \mathrm{M}$. A. Hamad, Magnetocaloric effect of perovskite $\mathrm{Eu}_{0.5} \mathrm{Sr}_{0.5} \mathrm{CoO}_{3}$, J. Supercond. Nov. Magn. 27, 277-280 (2014).

${ }^{6}$ M. A. Hamad, Magnetocaloric effect in (001)-Oriented MnAs thin film, J. Supercond. Nov. Magn. 27, 263-267 (2014).

${ }^{7}$ M. A. Hamad, Magnetocaloric effect in nanopowders of $\mathrm{Pr}_{0.67} \mathrm{Ca}_{0.33} \mathrm{Fe}_{x} \mathrm{Mn}_{1-x} \mathrm{O}_{3}$, J. Supercond. Nov. Magn. 27, 223-227 (2014).

${ }^{8}$ M. A. Hamad, Magnetocaloric effect in $\mathrm{La}_{1.25} \mathrm{Sr}_{0.75} \mathrm{MnCoO}_{6}$, J. Therm. Anal. Calorim. 115, 523-526 (2014).

${ }^{9}$ M. A. Hamad, Simulation of magnetocaloric effect in $\mathrm{La}_{0.7} \mathrm{Ca}_{0.3} \mathrm{MnO}_{3}$ ceramics fabricated by fast sintering process, J. Supercond. Nov. Magn. 27, 269-272 (2014).

${ }^{10}$ M. A. Hamad, Magnetocaloric effect in $\mathrm{Sr}_{0.4} \mathrm{Ba}_{1.6-x} \mathrm{La}_{x} \mathrm{FeMoO}_{6}$, J. Supercond. Nov. Magn. 27, 1777-1780 (2014).

${ }^{11}$ M. A. Hamad, Magnetocaloric effect in $\mathrm{La}_{0.65-x} \mathrm{Eu}_{x} \mathrm{Sr}_{0.35} \mathrm{MnO}_{3}$, Phase Transit. 87, 460-467 (2014).

${ }^{12}$ M. A. Hamad, Simulation of magnetocaloric properties of antiperovskite structural $\mathrm{Ga}_{1-x} \mathrm{Al}_{x} \mathrm{CMn}_{3}$, J. Supercond. Nov. Magn. 27, 2569-2572 (2014).

${ }^{13}$ M. A. Hamad, Lanthanum concentration effect of magnetocaloric properties in $\mathrm{La}_{x} \mathrm{MnO}_{3-\delta}$, J. Supercond. Nov. Magn. (2014). DOI: 10.1007/s10948-014-2834-3.

${ }^{14}$ D. Keogh, Z. Chen, R. A. Hughes, A. Dabkowski, O. Marinov, C. Maunders et al., (100) $\mathrm{MgAl}_{2} \mathrm{O}_{4}$ as a lattice-matched substrate for the epitaxial thin film deposition of the relaxor ferroelectric PMN-PT, Applied Physics A 98, 187 (2010).

${ }^{15}$ L. S. Kamzina, E. V. Snetkova, I. P. Raevskiǐ, A. S. Emel'yanov, J. Xu and W. Xiang, Evolution of the ferroelectric phase in $\langle 001\rangle$ oriented $(100-x) \mathrm{PbMg}_{1 / 3} \mathrm{Nb}_{2 / 3} \mathrm{O}_{3-x} \mathrm{PbTiO}_{3}$ single crystals, Phys. Solid State 49, 762 (2007).

${ }^{16}$ Y. Yang, Y. L. Liu, S. Y. Ma, K. Zhu, L. Y. Zhang, J. Cheng, G. G. Siu, Z. K. Xu and H. S. Luo, Polarized micro-Raman study of the field-induced phase transition in the relaxor $0.67 \mathrm{PbMg}_{1 / 3} \mathrm{Nb}_{2 / 3} \mathrm{O}_{3-0.33} \mathrm{PbTiO}_{3}$ single crystal, Appl. Phys. Lett. 95, 051911 (2009).

${ }^{17}$ T. M. Correia, J. S. Young, R. W. Whatmore, J. F. Scott, N. D. Mathur and Q. Zhang, Investigation of the electrocaloric effect in a
$\mathrm{PbMg}_{2 / 3} \mathrm{Nb}_{1 / 3} \mathrm{O}_{3}-\mathrm{PbTiO}_{3}$ relaxor thin film, Appl. Phys. Lett. 95, 182904 (2009).

${ }^{18}$ M. Zeng, S. W. Or and H. L. Chan, Giant resonance frequency tunable magnetoelectric effect in a device of $\mathrm{Pb}\left(\mathrm{Zr}_{0.52} \mathrm{Ti}_{0.48}\right) \mathrm{O}_{3}$ drum transducer, $\mathrm{NdFeB}$ magnet, and Fe-core solenoid, Appl. Phys. Lett. 96, 182503 (2010).

${ }^{19}$ B. J. Rodriguez, S. Jesse, A. N. Morozovska, S. V. Svechnikov, D. A. Kiselev, A. L. Kholkin, A. V. V. Shvartsman and A. L. Kholkin, Real space mapping of polarization dynamics and hysteresis loop formation in relaxor-ferroelectric $\mathrm{PbMg}_{1 / 3} \mathrm{Nb}_{2 / 3} \mathrm{O}_{3}-\mathrm{PbTiO}_{3}$ solid solutions, J. Appl. Phys. 108, 042006 (2010).

${ }^{20}$ M. A. Hamad, Room temperature giant electrocaloric properties of relaxor ferroelectric $0.93 \mathrm{PMN}-0.07 \mathrm{PT}$ thin film, AIP Advances 3, 032115 (2013).

${ }^{21}$ D. Saranya, A. R. Chaudhuri, J. Parui and S. B. Krupanidhi, Electrocaloric effect of PMN-PT thin films near morphotropic phase boundary, Bull. Mater. Sci. 32, 259 (2009).

${ }^{22}$ M. A. Hamad, Theoretical investigations on electrocaloric properties of (111)-oriented $\mathrm{PbMg}_{1 / 3} \mathrm{Nb}_{2 / 3} \mathrm{O}_{3}$ single crystal, J. Adv. Ceram. 2, 308-312 (2013).

${ }^{23} \mathrm{M}$. A. Hamad, Electrocaloric properties of Zr-modified $\mathrm{Pb}\left(\mathrm{Mg}_{1 / 3} \mathrm{Nb}_{2 / 3}\right) \mathrm{O}_{3}$ polycrystalline ceramics, J. Adv. Dielectr. 3, 1350029 (2013).

${ }^{24}$ M. A. Hamad, Detecting giant electrocaloric properties of ferroelectric SbSI at room temperature, J. Adv. Dielectr. 3, 1350008 (2013).

${ }^{25}$ G. Akcay, S. P. Alpay and G. A. Rossetti, Jr., Influence of mechanical boundary conditions on the electrocaloric properties of ferroelectric thin films, J. Appl. Phys. 103, 024104 (2008).

${ }^{26}$ Y. He, X. M. Li, X. D. Gao, X. Leng and W. Wang, Enhanced electrocaloric properties of PMN-PT thin Films with LSCO buffer layers, Funct. Mater. Lett. 4, 45 (2011).

${ }^{27}$ M. L. Calzada, M. Algueró, J. Ricote, A. Santos and L. Pardo, Preliminary results on sol-gel processing of $\langle 100\rangle$ oriented $\mathrm{Pb}\left(\mathrm{Mg}_{1 / 3} \mathrm{Nb}_{2 / 3}\right) \mathrm{O}_{3}-\mathrm{PbTiO}_{3}$ thin films using diol-based solutions, J. Sol-Gel Sci. Technol. 42, 331 (2007).

${ }^{28}$ Q. Zhou, Q. Zhang, B. Xu and S. Trolier-McKinstry, In-plane polarized $0.7 \mathrm{~Pb}\left(\mathrm{Mg}_{1 / 3} \mathrm{Nb}_{2 / 3}\right) \mathrm{O}_{3-0.3} \mathrm{PbTiO}_{3}$ thin films, J. Am. Ceram. Soc. 85, 1997 (2002).

${ }^{29} \mathrm{R}$. Nakagauchi and H. Kozuka, Preparation of $0.7 \mathrm{~Pb}\left(\mathrm{Mg}_{1 / 3} \mathrm{Nb}_{2 / 3}\right)$ $\mathrm{O}_{3-0.3} \mathrm{PbTiO}_{3}$ thin films via a polyvinylpyrrolidone-assisted aqueous sol-gel process and dielectric properties, J. Am. Ceram. Soc. 90, 3632 (2007).

${ }^{30}$ M. L. Santiago, M. G. Stachiotti, R. Machado, N. Pellegri and O. de Sanctis, Synthesis and characterization of PMN-PT thin films prepared by a new chemical route, Ferroelectrics 370, 85 (2008). 